\title{
Preferential Purchase of E-commerce Model in China
}

\author{
Ming Du \\ College of Management, Shangqiu University
}

\begin{abstract}
The popularization of the Internet has promoted the leap-forward development of e-commerce. In recent years, the increasing number of e-commerce platforms and merchants has led to a sharp increase in customer acquisition costs. Low-cost access to customers has become the main goal pursued by e-commerce merchants. The e-commerce Preferential Purchase model relies on the mainstream e-commerce platform to serve as a shopping guide for merchants of various e-commerce platforms. It provides multi-channel promotion and promotion of e-commerce products to increase customer traffic by saving money, rebates and making money. However, the credibility of the Preferential Purchase platform, the poor quality of products brought by low prices, the preferential procedures and the illegal behavior of the hierarchical agents have also become the bottleneck for the development of the Preferential Purchase model. Keywords: E-commerce; Preferential Purchase platform;Economical; Rebate
\end{abstract}

DOI: $10.36012 /$ ems.v1i1.956

\section{Introduction}

$\mathrm{W}$

ith the development of the Internet, the market environment is changing with each passing day. More and more people choose to shop online, and e-commerce has gradually become the mainstream of the times. While entering the traditional business users, e-commerce has also separated most of the profits of the traditional industry. Under the impact of the Internet economy, the physical store seems to be sorrowful, and the frequent closing of the store has become a "new normal". ${ }^{[1]}$ However, the e-commerce of the surface scenery, but also because of the rapid growth of e-commerce platforms and merchants, it also seems to be difficult. Behind the beautiful sales flow of e-commerce, it is to use a kind of "killing one thousand and self-defeat of eight hundred" to kidnap the interests of all parties, to achieve lower cost access to users and more efficient business growth. Goals of various e-commerce companies. ${ }^{[2]}$ Building a user growth team, transforming user growth methods, and improving user acquisition capabilities are the priorities of current e-commerce companies.
The continuous accumulation and growth of data and technology has led the community to become a new era trend, promoting the integration of community and e-commerce. Community e-commerce has a more precise and direct customer base through social promotion and marketing methods to achieve a "point-to-face" sales strategy. ${ }^{[3]}$ Low price is also the main way to enter the e-commerce platform and e-commerce enterprise marketing. The preferential promotion methods of Taobao, Tmall and Jingdong and other merchants are also low-priced expressions. [4] Based on the two-way bonus of social marketing and offers, the e-commerce Preferential Purchase model has sprung up. However, after several years of development, the popularity of the Preferential Purchase model is not high, and even most non-circle people have never heard of the related APPs of Preferential Purchase, and their trust is low. The Preferential Purchase model did not achieve the expected results. In the end, is there a bias in the understanding of the mode of Preferential Purchase, or is there a bottleneck in the development model? In-depth understanding and analysis of the Preferential Pur- 
chase mode is needed to find the answer.

\section{Interpretation of E-commerce Preferen- tial Purchase Model}

\subsection{E-commerce Preferential Purchase mode}

The e-commerce Preferential Purchase model, as the name suggests, is to bring more benefits to consumers. There are many ways to offer e-commerce offers, such as rebates, commissions, coupons, gifts, and low-priced purchases. In the mobile phone application market where the Android application system is loaded, the keyword " Preferential Purchase " is searched, and there are 112 purchase apps (only APPs with more than one thousand downloads are displayed). A summary of the application mode of such a purchase APP reveals that this model mainly focuses on the following three points.

(1) Money-saving tools: cooperate with first-line merchants such as Taobao and Tmall, collect preferential information of e-commerce platform and various coupons, quickly filter the latest hottest discount information through classification, and simultaneously assist in screening, first receive internal coupons, and then receive internal coupons. Shopping, discounts and then discounts, making purchases more favorable, become a consumer shopping assistant, helping consumers online shopping to save money.

(2) Rebate tools: Preferential Purchase merchants use the cooperation relationship between major online shopping malls and mall merchants to obtain sales commissions for such malls or merchants. Consumers go to Taobao and other major online shopping malls through the Preferential Purchase platform, and the purchasers will return a portion of the commission to the consumers, making the consumer shopping price more favorable.

(3) Money-making tools: Merchants absorb and retain customers through their own preferential models. When registered users purchase through the Preferential Purchase platform or go to other online malls, they can get the corresponding commission. At this time, the merchants also encourage and directly promote consumers to become partners or promoters, share the products of the purchasers in their own social channels, help the merchants to promote, obtain the commissions given by the merchants, and become a way to earn money.

It can be seen that saving money, rebates and making money become the main representatives of the purchase-purchase model. The coupons and commissions of mainstream e-commerce platform merchants such as Taobao, Tmall, Jingdong and Dangdang have become the foundation of Preferential Purchase merchants. It is more like an intermediary who integrates preferential resources. It is a platform for self-service Taobao merchandise coupons. Consumers can use the platform to self-check whether there are any offers for things to buy. It not only provides consumers with a better match for more favorable products, but also increases another consumption scenario for online shopping. For consumers, the increase in multi-scenario consumption not only saves money, but also promotes publicity through social means, and achieves the goal of increasing revenue in the way of customer acquisition. It is essentially a pure buyer guide platform that integrates discounts, rebates, and sharing. It provides services such as shopping cash back, exclusive discounted goods, preferential information, and a business model in which consumers can increase revenue through social promotion.

\subsection{The Preferential Purchase process and mer- chant comparison}

(1) The use process of the Preferential Purchase mode (1) Search and download the app in the mobile app store, then sign up (or register with the invitation code) and login;

(2)After logging in, you can search for the name of the product you want to purchase on the homepage;

(3) Find the discounted product you want to buy, click "Immediately receive the coupon" on the product homepage and then jump to the platform page such as Taobao;

(4) On Taobao and other platform pages, you can jump to the page to make a payment.

(5)You can also enjoy rebates after payment.

(6) After signing up for purchase with the invitation code, the promoter who sent the invitation code will also receive a promotion commission. Among them, sharing coupons, customer service, delivery, after-sales, etc. are completed by the Preferential Purchase platform.

(2) Comparison of the characteristics of Preferential Purchase platform

The core of the Preferential Purchase model is a platform that provides preferential information. In fact, the 
places where users consume, or the mainstream platforms such as Taobao and Jingdong, optimize the price choices for online consumers. By selecting the top four apps for the Android app market with " Preferential Purchase " as the keyword search and the APP directly named after " Preferential Purchase ", it is concluded that relying on Taobao and other mainstream e-commerce platforms is their guarantee, the Economical, Coupons, Rebates, and Pinch Pennies are the most common application tags, and low prices are the core of this model. The specific comparison contents are shown in Table 1.

Table 1. Preferential Purchase mode business characteristics comparison

\begin{tabular}{|c|c|c|c|c|}
\hline $\begin{array}{c}\text { Serial } \\
\text { number }\end{array}$ & $\begin{array}{c}\text { Preferential Purchase } \\
\text { merchants } \\
\text { (number of installations) }\end{array}$ & $\begin{array}{l}\text { Promotional } \\
\text { slogan }\end{array}$ & $\begin{array}{l}\text { Application } \\
\text { tag }\end{array}$ & Feature of product \\
\hline 1 & $\begin{array}{l}\text { Savings Express } \\
\text { (43.82 million) }\end{array}$ & $\begin{array}{l}\text { More than Taobao } \\
\text { Tmall directly buy } \\
\text { provinces } 50 \% \\
\text { definitely do not spend } \\
\text { a pen, } 9.9 \text { yuan } \\
\text { Shipping } \\
\text { limited time spike and } \\
\text { other special areas } \\
\text { low-cost good things. }\end{array}$ & $\begin{array}{c}\text { Economical; } \\
\text { Mall; } \\
\text { Parity; } \\
\text { Coupon }\end{array}$ & $\begin{array}{l}\text { (1) } 9.9 \text { yuan Shipping special: low-cost good things are } \\
\text { also Shipping, the whole network selects good goods, to } \\
\text { ensure the real low price. (2) } 1 \text { yuan spike: big-name good } \\
\text { goods, value-for-money products, explosions of goods, } \\
\text { non-stop. (3) One-click search coupon: Finding offers is } \\
\text { more convenient, Taobao Tmall coupons are searched } \\
\text { for with one click. (4) Newcomer limited time ( } 0 \text { yuan } \\
\text { purchase): buy things, do not spend money, new users to } \\
\text { place orders within } 24 \text { hours, the highest to receive } 10 \\
\text { yuan red envelopes, can be directly withdrawn. }\end{array}$ \\
\hline 2 & $\begin{array}{c}\text { Yitao } \\
(29.15 \text { million })\end{array}$ & $\begin{array}{l}\text { Alibaba's preferred sale } \\
\text { platform, the highest } \\
\text { return to } 81 \% \text {, the } \\
\text { exclusive private } \\
\text { coupons to place } \\
\text { orders; invite friends to } \\
\text { download additional } \\
\text { rebate rewards, save } \\
\text { the province. }\end{array}$ & $\begin{array}{l}\text { Shopping; } \\
\text { Shipping; } \\
\text { Pinch pennies; } \\
\text { Rebate }\end{array}$ & $\begin{array}{l}\text { (1) Affiliated to Alibaba Group: the goods are all, the } \\
\text { coverage is wide, the rebate amount is high, and the } \\
\text { official channels are safe and accurate. Taobao account } \\
\text { is common. (2) Exclusive coupons: updated daily, large } \\
\text { coupons are limited to one Tao channel, and cash is used } \\
\text { for coupons. (3) Sign in the collection of points: the } \\
\text { collection of treasures bound Alipay, pay directly when } \\
\text { the money. (4) There are many promotion activities: the } \\
\text { categories cover all, the synchronization is cost-effective, } \\
\text { and the selected activities of the rush to buy, save the } \\
\text { province. }\end{array}$ \\
\hline 3 & $\begin{array}{l}\text { Return and Save Money } \\
\text { Allianc ( } 21.78 \text { million })\end{array}$ & $\begin{array}{l}\text { A coalition app that is } \\
\text { dedicated to making } \\
\text { money for shopping } \\
\text { rebates, r online } \\
\text { shopping to rave } \\
\text { money, sharing money, } \\
\text { and money-saving } \\
\text { artifacts that online } \\
\text { shopping is } \\
\text { after. }\end{array}$ & $\begin{array}{l}\text { Economical; } \\
\text { Coupon; } \\
\text { Rebate; } \\
\text { Pinch pennies }\end{array}$ & $\begin{array}{l}\text { (1) The rebate is fast and the cash is up to } 95 \% \text {, which is } \\
\text { far ahead of other rebate apps. (2) Large internal coupons: } \\
100 \text { yuan or more of internal coupons are available every } \\
\text { day, saving money and super discounts. (3) Carefully } \\
\text { selected: Pick up big-name sales, select } 9.9 \text { shipping } \\
\text { items. (4) Easily earn money: not only share and promote } \\
\text { can make money, daily sign-in, share APP, sun-done, } \\
\text { sun-drink sharing, and product theory can make money. }\end{array}$ \\
\hline 4 & $\begin{array}{l}\text { Peanut Diary } \\
(21.12 \text { million })\end{array}$ & $\begin{array}{l}\text { Spend less money, } \\
\text { more money, referred } \\
\text { to as "peanuts", the } \\
\text { preferred } \\
\text { money-saving tool for } \\
\text { online shopping, the } \\
\text { large amount of } \\
\text { coupons to get soft, } \\
\text { sharing offers to save } \\
\text { you money all year } \\
\text { round. Really let you } \\
\text { achieve less money } \\
\text { and more money. }\end{array}$ & $\begin{array}{c}\text { Economical; } \\
\text { Share to earn } \\
\text { money; } \\
\text { Coupon; } \\
\text { Pinch pennie }\end{array}$ & $\begin{array}{l}\text { (1) Relying on Taobao Tmall and other mainstream } \\
\text { online malls: the project is stable, long-lasting, reliable, } \\
\text { zero threshold from beginning to end, zero investment, } \\
\text { zero risk. (2) Simple and easy to use: the user uses the } \\
\text { flower birthday note to be simple, the purchase product } \\
\text { system automatically distributes the profit, and the } \\
\text { commission is cashed out to Alipay on a monthly basis. } \\
\text { (3) Save money and fission: Users feel that they really } \\
\text { help him save money, recommend it to his relatives and } \\
\text { friends, generate recommendation fission, the more the } \\
\text { commission is earned. (4)Automatically lock fans: When } \\
\text { a user registers for a birthday, they will receive a unique } \\
\text { invitation code assigned by the system, and the invited } \\
\text { registrant will automatically become a permanent fan. }\end{array}$ \\
\hline
\end{tabular}


Continuation Table 1.

\begin{tabular}{|c|c|c|c|c|}
\hline $\begin{array}{l}\text { Serial } \\
\text { number }\end{array}$ & $\begin{array}{c}\text { Preferential Purchase } \\
\text { merchants } \\
\text { (number of installations) }\end{array}$ & Promotional slogan & Application tag & Feature of product \\
\hline 5 & $\begin{array}{l}\text { Preferential Purchase } \\
\qquad(92,000)\end{array}$ & $\begin{array}{l}\text { Save money and save } \\
\text { time shopping app, a lot } \\
\text { of coupons get your } \\
\text { hands soft, hot products } \\
\text { recommended farewell to } \\
\text { choose difficult, invite } \\
\text { friends to buy and cash } \\
\text { rewards. }\end{array}$ & $\begin{array}{c}\text { Economical; } \\
\text { Coupon; } \\
\text { Rebate; } \\
\text { Service }\end{array}$ & $\begin{array}{l}\text { (1) Service is guaranteed: Focus on online shopping } \\
\text { and save money for } 8 \text { years (online in February } \\
\text { 2011), serving millions of users, is recognized as a } \\
\text { small assistant to save money on online shopping. } \\
\text { (2) More cooperation websites: up to } 100 \text { home } \\
\text { appliance business websites. (3)Online shopping can } \\
\text { save money: Before you place an order, you can } \\
\text { use the purchase of APP to search for goods with } \\
\text { large coupons, and there will be rebates after the } \\
\text { order is placed. Selected value-for-money items, } \\
\text { price concessions are also practical. (4) Better } \\
\text { customer service: Provides you with exclusive } \\
\text { customer service, and the new service is for you. }\end{array}$ \\
\hline
\end{tabular}

Source: Android application market purchase mode APP information collection

\section{Preferential Purchase mode operation promotion method}

\subsection{Operation mode of the Preferential Purchase}

(1) Outsourcing cooperation model

After the Preferential Purchase platform and the mainstream platform merchants reach a cooperation agreement, they will dock the mainstream platform commodity category links, and the Preferential Purchase platform will be responsible for promotion and earning the difference or commission. This mode of Preferential Purchase platform will charge the service fee according to the promotion period.

(2) Outsourcing cooperative distribution model

Preferential Purchase platform contacts all platform merchants, negotiates with each brand merchants to provide the lowest cost price for product distribution to the platform for Preferential Purchase, and the platform for promotion is promoted at no higher than the market price, but the link and evaluation of customers' orders during the promotion process They are all shop links of brand merchants. This model is generally free to promote the platform, but earn a certain distribution profit.

(3) Self-operated mode

The retailer's home registration account on the Preferential Purchase platform, and a special person responsible for product release, the release of product styles and categories. After the link is generated by the Preferential Purchase platform, it will be released to other channels for promotion. The Preferential Purchase platform will charge the annual fee according to the product release. This model is suitable for large-scale purchase of e-commerce companies to clear inventory and fan operations.

\subsection{Promotion mode of the Preferential Purchase mode}

Due to the characteristics of its shopping guide, the purchase-purchase model has become the new darling of the e-commerce industry. Compared with the traditional e-commerce sellers' operation mode, this model attracts the e-commerce merchants in the new era with its unique advantages of no supply, no inventory and no risk. The employee group is extended to students, treasures and white-collars. Waiting for the crowd. This type of employee group mainly uses their free time to promote and promote through social networks, which is the main reason why the Preferential Purchase model belongs to the community e-commerce. ${ }^{[5]}$ The biggest difference between social e-commerce and Ali, JD.com's online platform sales model is that its sales target is more stable and more accurate. When a community attracts members, then those members become stable customers. Therefore, the promotion methods of most Preferential Purchase models take two categories:

(1) At the merchant level: mainly promote the promotion of business apps and websites, adopt the comment area of the cooperation platform merchants to promote maps, APP download benefits (coupon rewards) promotion, public number operation promotion, Baidu promotion, self-media promotion, community promotion, etc. ${ }^{[6]}$ 
(2)Employee level: Focus on product or low-price promotion, use the social network of part-time people to promote the level, and expand the marketing level step by step.

\section{Potential problems in the e-commerce Preferential Purchase mode}

With the popularity of e-commerce and the pressure of traditional direct sales to face strong supervision and public opinion, some domestic direct selling companies have transformed the community e-commerce model of Preferential Purchase, which has seized new development opportunities, but in the process of operation, There are many loopholes and problems in regulating operations, which are manifested in the following aspects.

(1) The credibility of a large number of Preferential Purchase platforms needs to be improved

From the rise and development of the original Taobao guest rebate website, the Preferential Purchase platform has blossomed like a mushroom, and a small website and APP have entered the market for promotion. But not all platforms are trustworthy. The promotion of phishing websites has been deeply rooted in people's hearts. In particular, some small platforms will face bankruptcy at any time because of poor management. ${ }^{[7]}$ For example, the recent e-commerce platform " Preferential e-Purchase " low-priced goods but not shipped without refund, the police has filed a case for investigation. Although the Preferential Purchase platform claims to only receive discounts on its platform, all transactions are on mainstream e-commerce platforms such as Taobao, enjoying the same pre-sales and after-sales services as mainstream platform users. However, the transit of information and the circulation of secondary channels of products make it difficult to believe the feasibility of the sustainable operation of the Preferential Purchase platform and the feasibility of the business model in the case of low prices.

(2)Low price leads to product quality cannot be guaranteed

A major problem with the purchase platform is how to meet the customer's requirements for product quality. All of the products that can be searched in the Preferential Purchase platform are non-popular brand products, and the product cost is low. Such products belong to the brand's merchants to use the Preferential Purchase platform to do the drainage service, and are will- ing to let more profits to the platform to earn store ratings, store reputation, store sales, etc., to improve the comprehensive index of online stores, bring them free volume and platform resources. In addition to branded products, it is a personal store on Taobao and other platforms. It also promotes profits in order to obtain volume, but most of the product quality cannot be guaranteed.

(3) Rebate or preferential threshold is high, and there are many routines

Discounts, rebates, cash withdrawals or non-cash; can only receive discounts, no commissions; some merchandise commissions; virtual standard cash back, invite friends to click to withdraw cash, and other cash and cash back offers will make consumers greedy. The feeling of eating a big loss is cheap. For example, the zero-yuan purchase of the money-saving express newspaper advertisement, but not the zero-yuan purchase in the true sense, but the need to buy and then cash back, the withdrawal needs to wait for a long time, and set the invitation friend to buy or raise the amount of cash according to the number of subsequent purchases. Cash back and so on.

(4)Hierarchical agent promotion method analogy MLM

The social e-commerce model of the Preferential Purchase platform adopts the customer acquisition method of social-level agent distribution. Although the agent distribution has brought volume and performance to the platform for Preferential Purchase in a short time, some still use the multi-level distribution method illegally, which leads to the development of offline and downward pressure to make profits[8]. In March 2019, " Peanut Diary " was suspected of pyramid schemes (direct sales) illegal activities, the operating company "Guangzhou Peanut Diary Record Network Technology Co., Ltd." (hereinafter referred to as the birthday card) was fined 1.5 million yuan, and was confiscated illegal income of 73.06 million yuan The cumulative penalty was not more than 74.56 million yuan. Under this circumstance, product quality and after-sales service are difficult to guarantee, and the hidden dangers of social commerce such as high price are beginning to become more prominent.

\section{Conclusion}

In recent years, the development and popularity of mobile Internet, online shopping has been regularized. 
Low prices are still one of the labels most people define for online shopping. Based on the demand of consumers for online shopping products and the need for online merchants to promote sales, the e-commerce Preferential Purchase mode came into being. From the current overall situation, e-commerce Preferential Purchase is a pure buyer guide platform that integrates discount, rebate and sharing. It provides services such as shopping cash back, exclusive discount products, preferential information and other business models through social promotion. It mainly has three modes of operation: outsourcing cooperation, outsourcing cooperation distribution and self-operation. Social communication has become a major application promotion tool, both at the merchant and employee levels. It is also this kind of community agent promotion method that has caused some of the Preferential Purchase platforms to adopt illegal multi-level distribution methods, and there are illegal means similar to pyramid schemes. The credibility of the multi-purchasing platform, the low price of the product, the guarantee of product quality, the rebate or the preferential package have become the bottleneck for the purchase platform. In short, the e-commerce Preferential Purchase mode uses its own money to save money, and the way to share the money needs to be cautious. After the purchase-purchase mode breaks through its problems and withstand the market test, it can truly become a good mode for e-commerce transformation.

\section{References:}

[1] NIE Lin-hai.(2016).The Innovative and Standardized Development of E-commerce in China[J].China Business And Market,30(6):52-57.DOI:10.14089/j.cnki.cn11-3664/f.2016, 06,008 .

[2] YU Hua.(2016).China's Wechat Business as New Formats: The Current Situation, Development Trend and Countermeasures [J].China Business And Market,30 (12):47-56. DOI:10.14089/j.cnki.cn11-3664/f.2016.12.006.

[3] Huang xiao-yin.(2019).The Association of Social Economy, E-commerce and New Marketing Model [J].Research of Business economics,35(7): 75-77.

[4] Yao Qi, Cui Changqi.(2017).Effect of Cyber Cues of Recommended Commodities by E-business on Consumers' Purchase Intention [J].Contenporary Economic Management,39(11):22-30.DOI:10.13253/j.cnki.ddjjgl.2017,11.004.

[5] HAN Lin-lin.(2019).Innovation and Impact Analysis of Social Shared Retail in the Background of Mobile Social Dividend [J]. China Business And Market,33 (8):91-98.DOI: 10.14089/j.cnki.cn11-3664/f.2019.08.010.

[6] Wu Chao,Rao Jiayi,Qiao Han,Hu Yi,Wang Shouyang. (2017).Business Model Innovation of We Media Based on Community Economy - A Case Study of "LuoJi Thought" [J].Management Review,29 (4):255-263.DOI:10.14120/j. cnki.cn11-5057/f.2017.04.022.

[7] Li Jiangfeng,Wang Wei.(2018).Research on Identification and Analysis Methods of Phishing Websites[J].Communications Management and Technology,33(3): 62-64.

[8] HAN Lin-lin.(2010).Innovation and Impact Analysis of Social Shared Retail in the Background of Mobile Social Dividend [J].Commercial Research,39 (12): 191-196.DOI: 10.13902/j.cnki.syyj.2010.12.022. 